\title{
Final implementation of SEACON: new scope and new open system platform.
}

Mahou A.L.. Soto F. J., Blanco, $F$.

Red Eléctrica de España. S.A.

P. Conde de los Gaitanes, 177

28109 Madrid (SPAN)
Pastor G., Serna J., Alfageme M.A. Grupo Apex, S.A. C/ Sáinz de la Calleja, 14 28023 Madrid (SPAIN)

\author{
Corera J., Criado R, \\ Ferrer $\mathrm{V}$. \\ Iberdrola, S.A. \\ C/ Gardoqui, 8 \\ 48008 Bilbao (SPAIN)
}

Martín J.,

Garcia-Santesmases.J.M.

Universidad Complutense de Madrid

\begin{abstract}
tbstract - SEACON is a hybrid (heuristic \& algorithmic) expert system for contingency analysis and preventive or corrective control of the transmission network, that has been recently redesigned to implement new end user requirements and to increase its performance. This paper describes the main results and the operational experience from the development and implementation of a new system based on the initial idea. Software reuse strategies became capital in this project. The new design includes advanced functionalities demanded by the practical use of the former system. Because of the high performance of the new system (up to fifteen times faster than the original) and its friendly user interface, SEACON has become a very valuable tool among dispatchers. SEACON is in operation in the Red Eléctrica's National Control Centre and in Iberdrola's Central and Regional Control Centres, dealing with transmission and subtransmission networks (ranging between $400 \mathrm{kV}$ and $66 \mathrm{kV}$, attached to the on-line state estimators and screening over $\mathbf{2 0 0 0}$ possible contingencies. Results are presented using natural language, and a client-server scheme provided for corporate access.

Keywards - Expert system, security assessment, contingency analysis, power systems, real-time system, software reuse.
\end{abstract}

\section{INTRODUCTION}

Security control is one of the most important aspects in power systems operation. Power systems are designed and should be operated to survive to all possible contingencies within the company security criteria. Energy Management Systems (EMS) implement functionalities to monitor the svistem security. The main one is contingency analysis (CA) which assess the impact of a predefined set of contingencies on the power system. This tool is being widely implemented in EMS's from the mid of 80 's. However, security analysis has evolved since then. New domains can be processed in near real time. such as dynamic stability and voltage collapse.

Steady state contingency analysis has also progressed substantially thanks to the availability of Artificial Intelligence techniques. The selection of contingencies, the evaluation of their consequences and the search for corrective actions are getting more sophisticated. It is the case of the SEACON system and its evolution, presented in this paper.
In 1988 Red Eléctrica de España (REE), the Spanish publ utility that owns and operates the transmission network. an Iberdrola (IBD), the first utility in Spain. decided to develo an expert system that would reinforce the security in th operation of their respective power systems. That systen named SEACON was initially coded in LISP in proprietary system (GENERA operating system on Symbolics computer) and was implemented i IBERDROLA Control Centre in 1991 and in Red Eléctric North Regional Control Centre in 1993.

The limitations of the Symbolics platform -the manufacture had ceased the production, and no new models wer available- were preventing the two utilities to install th system addressing larger network models. such as th Spanish model or meshed distribution levels. In additior end users had proposed several new features to improve th system, including user interface issues.

REE and Iberdrola decided to port the system to an ope environment. and to redesign it to include those demande new functionalities. The project was developed jointly wit GRUPO APEX, S.A., an active company in the Energ domain with a strong knowledge of Mathematics.

End users experiences in the original system have bee applied in the new development in order to carry out ner improvements: automatic contingency screening includin user selected ones, complex contingencies analysis usin multiple post-compensation of Fast Decoupled Load Flon reactor contingency analysis, overvoltage contingencie treatment, integrated solutions screening, etc.

This new SEACON has been installed in the REE? National and North Regional Centre and in Iberdrola Central and Regional Control Centres in 1996.

\section{BACKGROUND}

In this section the initial system SEACON is briefl described. See ref. [5] for more details. This old system wi] be called as SEACON-I.

Some definitions were established in the first project: whic have been also used in the new one:

The limits established for SEACON are related to th expected operator's action. Two sets are considered:

- Level 1 or immediate action limits. which cannot b violated any time, corresponding to physical o protection limits. Control actions in the presence 0 contingencies producing a violation of these limits wi 
always be preventive.

- Level 2 or temporary limits, which can be tolerated during the average dispatcher's reaction time after an incident. Control actions can, here. be corrective.

The contingencies, according to the definition of limits. are classified as level 1 contingencies when they cause at least one violation of level 1 limits. the most dangerous ones, and. as level 2 contingencies, when only cause violation of level 2 limits

The security criteria used is the loss of a unique element ( $n$ 1). simple or complex

The network states are defined according to the following terminology:

- Vormal state: no magnitude exceeds its limits; the security criteria are achieved.

- Alert state: no limit violations but the security criteria are not fulfilled.

- Emergency state: one or more variables are outside their limits.

SEACON-1 has been running using the EMS State Estimation output to define the network image. called Base Case or Network Current State. Single Contingencies were studied and predictive or corrective solutions provided to the users, to avoid or lighten the potential problems, depending on its severity.

The system was solving contingencies according to the following sequence: first, once an $\mathrm{SE}$ solution was received. the sensitivity matrices were calculated. and the list of possible contingencies prepared: then the overload analysis and the voltage analysis modules were executed in this order.

\section{Overload contingencies methodology.}

First. the system tested whether the base case contained overloads in origin. In that case, it would pass the control to the solutions search module and once this is done, it would analyse the contingencies and their corresponding solutions. These steps are briefly explained in sequence.

- Selection and ordering of contingencies.

No filtering was done for single contingencies: the complex ones were filtered using heuristhical criteria. The selection of contingencies was done using sensitivity coefficients, estimated from the impedance matrix. Contingencies were ordered using a performance index.

- Search and testing of solutions.

SEACON-1 carried out the search of solutions for each overload produced by each contingency. Both local and global solutions were treated, and a decision tree was used to select the most appropriates ones. The tree was generated analysing the solutions experts had given in overload problems, first starting with local solutions, then the global ones, including generation changes and, finally, load shedding.
Voltage contingencies methodology.

Only undervoltages were considered in this voltage/reactive module. Voltages were monitored restricted to the buses defined as 'pilot buses', selected by power system operators or system engineers.

- Selection of harmful contingencies.

Initial undervoltages were detected in the same way than in the overload modules. If initial violations were detected, control was passed directly to the solutions modules, and once it was done. the normal contingency selection procedure was performed. This submodule was performed in two steps. Former. three consecutive heuristic criteria, and latter, an analytical ranking procedure was employed.

- Analysis of selected contingencies.

The selected contingencies were solved up to a certain mismatch tolerance by a fast decoupled load flow using postcompensation techniques. At this point. the control action determination submodule was called to find the solutions that would be advisable to operators in order to correct the limit violations.

- Preventive and corrective control actions determination.

A hierarchical procedure was used to correct voltage problems. For each contingency, the system begins with the worst violation. In order to solve it, the higher priority and closer available control action is considered. If necessary, other control actions are considered. always beginning with the closest available of the remaining ones. All voltage violations are treated in the same way, and the procedure ends when corrective action for all of them has been found, or when there are no more ways to improve the voltage profile

\begin{tabular}{|c|c|c|}
\hline TECHNIQUES & Heuristics & Algorithms \\
\hline $\begin{array}{l}\text { Overload } \\
\text { contingencies } \\
\text { selection }\end{array}$ & $\begin{array}{l}\text { - Contingencies } \\
\text { filtering. } \\
\text { - } \text { Performance index. } \\
\text { User selected } \\
\text { contingencies. }\end{array}$ & $\begin{array}{l}\text { Sensitive coefficient } \\
\text { and impedance } \\
\text { matrix based } \\
\text { algorithms: }\end{array}$ \\
\hline $\begin{array}{l}\text { Voltage } \\
\text { contingencies } \\
\text { selection }\end{array}$ & $\begin{array}{l}\text { Pilot buses } \\
\text { selection. } \\
\text { Heuristic filters. } \\
\end{array}$ & $\begin{array}{l}\text { Fast decoupled load } \\
\text { flow using } \\
\text { postcompensation } \\
\text { techniques }\end{array}$ \\
\hline $\begin{array}{l}\text { Search of } \\
\text { solutions }\end{array}$ & $\begin{array}{l}\text { Influence area } \\
\text { selection. } \\
\text { decision tree for } \\
\text { overload. } \\
\text { Hierarchical } \\
\text { solutions searching } \\
\text { for voltage. }\end{array}$ & \\
\hline $\begin{array}{l}\text { Testing of } \\
\text { solutions }\end{array}$ & & $\begin{array}{l}\text { Voltage sensitive } \\
\text { matrices. } \\
\text { Sensitive and } \\
\text { impedance } \\
\text { matrices } \\
\text { Power Flow } \\
\text { System (PFS) }\end{array}$ \\
\hline
\end{tabular}

Table I Techniques used in SEACON 


\section{NEW FEATURES}

The new system, called SEACON-2, has been the result of a deep analysis of the basic functionalities of SEACON-I and end user requirements (table 1). Main targets to develop SEACON-2 were:

- To include all the operators' needs arisen during the use of SEACON-1.

- To improve the user interface including a more friendly aspect and behaviour.

- To increase the system performance allowing to deal with greater networks.

- To achieve a full portable code. capable to run under Open Systems, and therefore with no limits in the type of machine to be used.

The specified functional improvements for the project are:

System architecture.

SEACON-2 is a POSIX compliant development, coded in ANSI-C and FORTRAN-90 under UNIX. User interface is coded in ANSI-C using Motif libraries. The portability of the new code has allowed to install the system in two different platforms: IBM RS6000 under AIX for REE system and Sun SPARC 10 under SOLARIS for IBD one.

Selection of contingencies and analysis.

a) Overvoltage contingencies: So far the contingencies studied were those causing overloads in lines or transformers. undervoltages in bus bar, and finally islands (unmeshed nodes). Now, overvoltage violations in bus bars are also analysed. As in undervoltage violations. two limits are defined for each bus bar: alert and emergency limit. This analysis may be important during low demand periods. Overload analysis also considers loss of reactors.

b) Three winding transformer loss: Although the EMS models these transformers as three two winding transformer. now the systems treated them as a single special (three winding) transformer. This improves the end user comprehension and allows the use of a faster algorithm based in a sensitive matrix.

c) Compound contingencies selected by user: The original system only analysed single contingencies (loss of one of the following: circuit line, multiple-end circuit. transformer, generator or bus bar). The new system is capable to deal with compound contingencies: coordinated generator and circuit tripping (loss of circuit and generator) and general compound contingencies (loss of any combination of network equipment to be tripped simultaneously). SEACON-2 uses an user precompiled list.

d) Integration between overload and voltage contingencies: They were processed separately in SEACON-1. because of the different methodologies used (sensibility and impedance matrices methods in overload and decoupled load flow in voltage), and were presented to the operators in two separate groups. Now the list of contingencies is unique; one contingency listed can cause overload and voltage violations simultaneously.

e) Generation contingencies analysis has been redesigned, modelling the effect of primary regulatio over the transmission network.

f) Generator representation has been improved including more detailed excitors and governors model The machine transformer has been included in th network image.

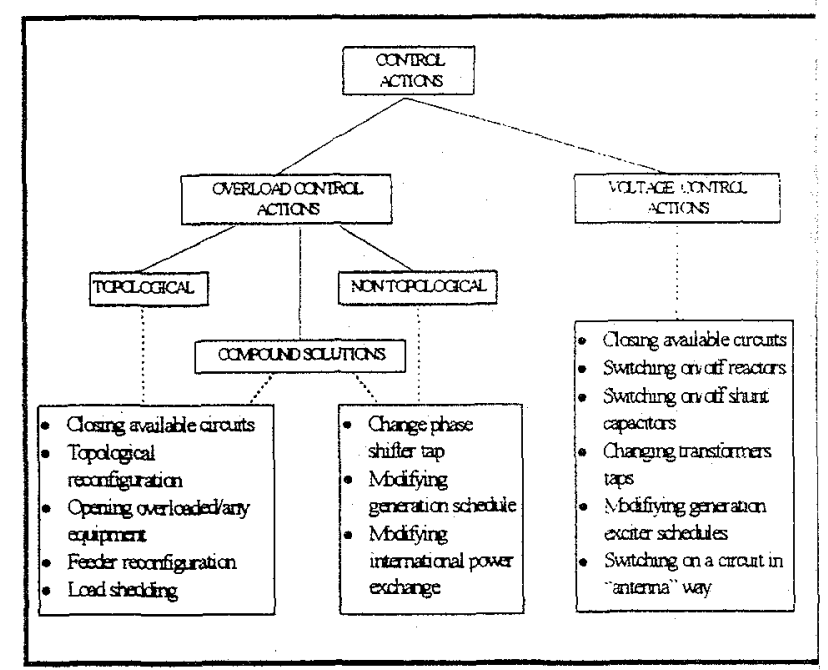

Fig. I Control actions for solving violations

Search and testing of solutions.

New kinds of control actions (solutions) have been included to solve jointly overload and voltage violations. As in the original system, the strategy and type of solutions used fo solving overload violations (independent solutions) diffe from those used for voltage (stacked solutions), see fig 1 The new functionalities are the following:

Overload control actions:

a) Solutions searching has been optimised in order t? provide those solutions that would solve or alleviate the maximum number of violations due to the same contingency.

b) Influence zone selection has been improved th minimise swing bus effect over close overloads.

c) Modifying generation schedule: SEACON-1 onl worked with two generators simultaneously in eaci solution. In the new system, generation changes to alleviate overloads may include more than two generators, in order to achieve a way of reasoning close to the operators' one

d) Improvement of the search for closing available circuits: A fast algorithm based in the sensitive matri: has been developed to determine accurately the effect over the network of closing a circuit. In the origina system, this solution was only approximate.

e) Load reconnection: The new system considers loac reconnection between splitted bus bar.

f) Combination of operations is considered wher looking for overload solutions. Experts defined the logit to be used when combining operations. It can bo 
expressed as follows:

- When only topological solutions are found the system investigates the combination of several nontopological operations. such as generation change or tap change

- When solutions consist of single non-topological operations, they would be accepted as valid ones.

- When the system cannot find non topological single solutions, it would search for combinations of topological and non-topological single operations.

In addition to changing voltage setpoints in generation busbars and transformer tap changers. voltage violations are solved: switching capacitors and reactors and leaving lines connected in antenna -just one end connected- this last action to increase voltage in the connected end.

Integration between overload and voltage control actions: When a contingency produces overloads and voltage riolations, the system checks the effects of the overload control actions over the bus voltages. This is an important improvement. not only because an overload solution can also solve a voltage violation, but because of the security level the control action has. Original system did not check the effects of overload solutions on voltages, nor voltages solutions on overloads.

\section{Vew simulator module}

The new system includes a simulator module that allows the user to execute any control action (fig. 2). In the network, followed by a complete contingency analysis, the operator can chain series of control actions and subsequent analysis, and then return to any intermediate state for checking different control hypothesis.

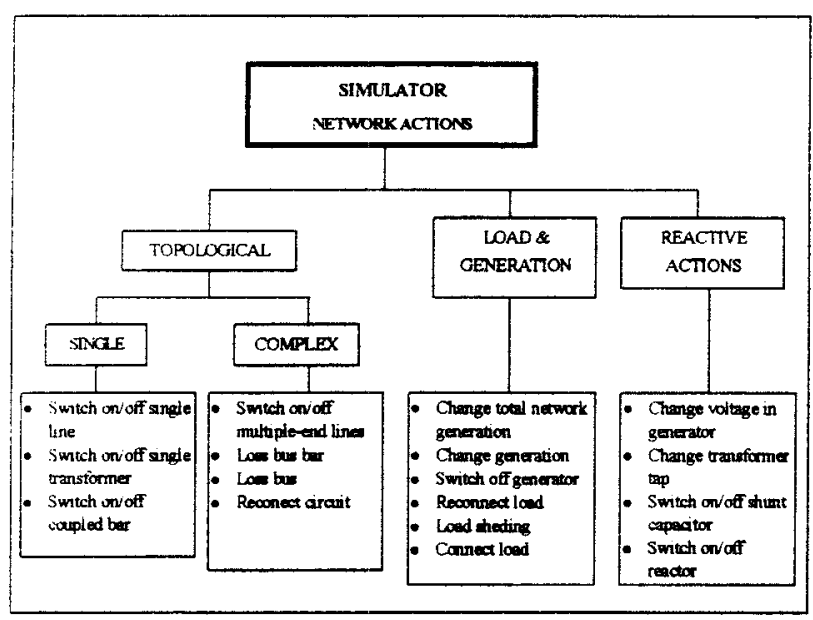

Fig. 2 Network operations in simulator module.

User interface.

The new user interface is Motif based and includes a graphic representation of the security level of the power system. Network states are associated to semaphores, representing the normal state as green light, the level 2 alert as vellow, the level 1 alert as orange and the emergency state as red. SEACON-2 shows separately the state of different voltage level networks. The contingencies overloads or voltages, are also shown by coloured LED's Figure 3 illustrates this idea. The colour code is the same used in the main window to manage the system outputs. The user interface also includes an alarm processor allowing the operator to manage the contingencies causing violations as acknowledgeable alarm items. Two modes are possible: to show all contingencies causing problems: or just to show unacknowledged ones. Using this second mode. the sistem offers users incremental behaviour. helping to detect emerging problems.

\section{DEVELOPMENT STRATEGY}

The initial system was developed in Lisp and implemented in a Symbolics XL400 machine. Due to its lack of portability, the system was ported from GENERA operating system to UNIX and Lisp code was translated. (using CHESTNUT Lisp-to-C translator), to a standard $C$ code.

Although the transiator produced ready to use $C$ code. it was optimised in order to improve system performance and to minimise memory requirements. Furthermore, user feedback was applied to the $C$ prototype to obtain the final system with the new features. At present, the system is fully portable and is running on an IBM RISC -6000 3BT (with AIX 3.2) and on a SUN SPARC-20 (with SunOS 4.1.3)

The user interface was built from scratch in Motif (1.2. The user interface menu driven and has been developed ver closely to the users. It has two main windows: The analysis window where the contingency analysis results are presented, and the network state window. This last window provides a quick overview of the security level of the ststem It contains three coloured semaphores, showing initial network violations and level 1 and 2 contingencies for three voltage levels $(400,220$ and bellow $132 \mathrm{kV})$. In addition. the "acknowledgement" mechanism allows the user to filter known contingencies -i.e. structural contingencies-. so he can pay attention to new ones.

The structure of the system is highly modular. making easier its connection to different EMS's. Essentially. it is composed on the reasoning core, the analytical modules. the EMS interface and topology generation and the user interface.

\section{OPERATIONAL EXPERIENCE AND FURTHER WORK}

SEACON-2 has been installed in the REE national control centre in June 1996, and in IBD control centres in July 1996.

The REE's model includes 1,800 busbars. 780 line circuits. 600 transformers, 400 generators, 650 loads and 70 reactors. SEACON-2 processes every converged solution from the state estimator. The average response time of the system. including data transmission from the EMS, contingency analysis and solution searching, is around 5 minutes. running under IBM RS6000 3CT. This time means 15 times faster than SEACON-1 (table 2).

In order to minimise the delay to show the contingencies 
causing problems, the system shows the selected contingencies and the resulting violations prior to searching for their solutions, which are displayed when found (individually). SEACON-2 begins to search the solutions starting from the worst violations.

SEACON-2 was installed in the Iberdrola central Transmission and Distribution Dispatch Centre, located in Bilbao. and in the Regional Dispatch Centre in Valencia. The first analyses the $400 \mathrm{kV}$ down to $132 \mathrm{kV}$ North-WestCentral network, using a model of 430 electrical nodes. The second installation analyses the East region, which is loosely coupled to the former one. Here the model goes down from the transmission levels to the meshed $66 \mathrm{kV}$ distribution network, including a total of 465 electrical nodes. In addition to the embedded interface, SEACON results are stored in a corporative Oracle database, making them available to most of users.

SEACON-2 allows to manage, in study mode, historic scenarios from databases, different from the current one, preventing the classical problems due to database maintenance. End user feedback became capital along this project. They suggested new requirements for this system and they have collaborated during the product test phase, providing an useful information to adapt the system to the dispatch needs. Thanks to this collaboration. operators are much more confident in SEACON-2 results. The experience gained from this project is leading to new improvements in three areas:

- To include automatic one-line representation with navigation, zooming and panning facilities.

- To enhance the contingency selection and screening improving compensated FDLF algorithm.

- To manage overloads caused by high reactive flows.

- Full integration of the SEACON-2 in EMS environment

- To carry out some dynamic security considerations, mainly the detection of voltage collapse proximity.
An important initial effort in SEACON-I was denoted cope with the different network representations within th REE and IBD EMSs. A standardisation ESPRIT project hi been initiated (codename "electronet") aiming to po SEACON and other applications to a widely accepte standard.

\section{Conclusions}

SEACON-2 project has reached its main target: to get a on-line decision aid tool for real-time operation. with a fa response time and a friendly interface accomplishing tt end-users needs and requirements. New improvements hav given a great flexibility to the system and allow a deept analysis.

The experience has been quite satisfactory in terms 0 robustness, low maintenance needs -the automatic selectio of contingencies has been quite appreciated- and goo results in the several months of operation of the fina system. Several unexpected potential dangerous situations due to scheduled maintenance- have been detected an appropriate actions taken

The costs of analysis and development phases of this systei have been reduced by software reuse techniques. Th extensive use of LISP to $\mathrm{C}$ translator to migrate the origin software and the integration of the new features in th already translated source code minimised costs and risk guaranteeing the high quality of the results. Actually, th test phase showed that the old code was running error fre in the new implementation.

Knowledge base reuse also reduced the analysis phase allowing an incremental approach to the final system. $\mathrm{Th}$ base expert core has been preserved and the calculus modul has been the more changed one.

\begin{tabular}{|c|c|c|c|c|}
\hline & & $\begin{array}{l}\text { REE National } \\
\text { Control Centre } \\
\text { in Madrid }\end{array}$ & $\begin{array}{l}\text { Iberdrola Central } \\
\text { Dispatch Centre } \\
\text { in Bilbao }\end{array}$ & $\begin{array}{c}\text { Iberdrola Regional } \\
\text { Dispatch Centre } \\
\text { in Valencia }\end{array}$ \\
\hline \multirow{8}{*}{ Network Model } & Transmission levels & $132,220,400 \mathrm{kV}$ & $132,220,400 \mathrm{kV}$ & $66.132,220,400 \mathrm{kV}$ \\
\hline & Buses & 1000 & 430 & 465 \\
\hline & Bus bars & 1800 & 834 & 917 \\
\hline & Circuits & 780 & 675 & 634 \\
\hline & Transformers & 600 & 189 & 365 \\
\hline & Generators & 400 & 88 & 22 \\
\hline & Loads & 650 & 294 & 256 \\
\hline & Reactors & 70 & 51 & 22 \\
\hline \multicolumn{2}{|l|}{ Computer System } & $\begin{array}{c}\text { IBM RS } 60003 \mathrm{BT} \\
\text { I28MB }\end{array}$ & $\begin{array}{c}\text { SUN SPARC-20 } \\
64 \mathrm{MB} \\
\end{array}$ & $\begin{array}{c}\text { SUN SPARC-10 } \\
64 \mathrm{MB}\end{array}$ \\
\hline Average of & High load & 105 & 12 & 30 \\
\hline Contingencies detected & Low load & 60 & 6 & 16 \\
\hline \multirow[t]{2}{*}{ Wall clock time } & High load & $505^{\prime \prime}$ & $135^{\prime \prime}$ & 228 \\
\hline & Low load & 4'20'” & l'10', & 2'08'” \\
\hline
\end{tabular}

Table 2 Systems statistics and timing analysis 


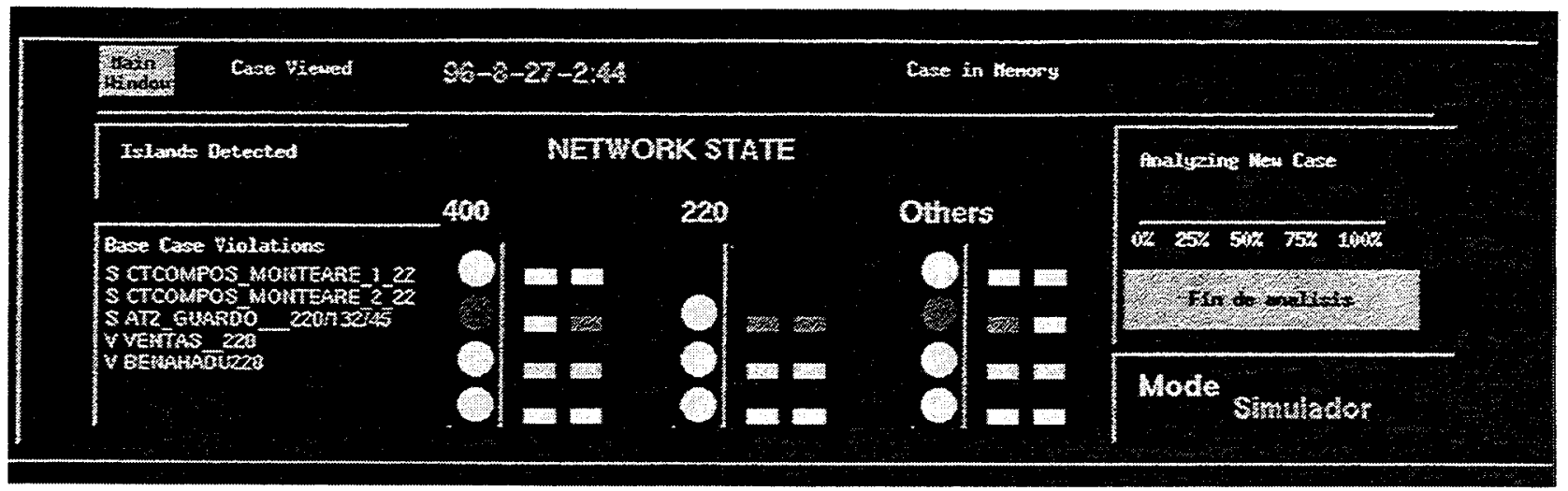

Figure 3: Network state window

\section{BIOGRAPHY}

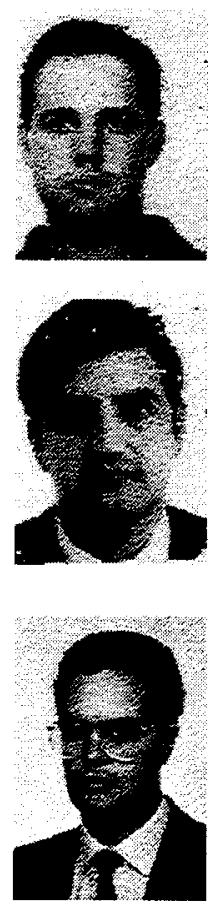

Angel L. Mahou was born in Madrid, Spain, on August 13. 1965. He graduated in Industrial Engineering (1989) at the Politécnica (nniversity of Madrid. Master in Energetic Technologies (1993) by the Politécnica University of Madrid

Mr. Mahou worked in Trans Tools S.A. for one year. Now he has been employed by Red Eléctrica de España. S.A since 1990 as Team Leader of Operation Aiding Projects.

Gerardo Pastor was born in Madrid. Spain. on October 30, 1963. He graduated in Mathematics in 1986 at the Universidad Complutense de Madrid. Mr. Pastor worked in I.D.S. for four vears. Now he has been employed by GRUPO APEX, S.A since 1990 as Energy Division Manager.

Mr. Pastor is .tssociate Professor at the Statistics and Operation Research Department in the Universidad Complutense de Madrid.

José Corera was born in Bilbao, Spain in 1961. He received his degree in electrical engineering from the Escuela Superior de Ingenieria de Bilbao in 1985. He received his MSc. from Cranfield Institute of Technology in UK in 1986. Mr. Corera joined Robotiker, an automation consultant firm in Spain in 1986, being responsible for Robotics and Artificial Vision. In 1989 he joined Iberdrola being currently responsible for the advance developments group in the Control Systems Department, specialized for network management applications and data base applications.

\section{ACKNOWLEDGEMENTS}

This work is included and supported by funds provided by the 'Plan de Investigación Electrotécnica' (PIE) from the Industry and Energy Spanish Ministry.

The contribution of

- Red Eléctrica National and North Regional Control Centres staff and

- Iberdrola central Transmission and Distribution Dispatch Centre and the Regional Dispatch Centre in
Valencia

has been essential to achieve the development and implementation of this system.

\section{REFERENCES}

[1] Bertram, T.J., Demaree, K.D., Dangelmaier, L.C., “An integrated package for real-time security enhancement". 1989 IEEE Power Industry Computer Application Conference, May 1.989, pp 360-366.

[2] Brandwajn. V., Lauby, M.G.. "Complete bounding method for A/C contingency screening". IEEE Transactions on Power Systems, May 1.989. pp 724729.

[3] Christie, R.D. Talukdar, S.N., Nixon. J.C. "CQR: A hybrid expert system for security assessment". 1989 IEEE Power Industry Computer Application Conference, May 1.989. pp 267-273

[4] J.Corera, J.Echávarri, F.Lasheras. J.Santamaria. J.Pérez, J.Barandiarán "Development and Installation of an Achitecture for Power System Restoration in two Spanish Utilities" CIGRE 1996 Session, Paris

[5] R.Criado, D.Matauco, F.Lasheras. J.L.Fernández. P.Basagoiti. J.Serna "An on-line Expert System for Contingency Analysis and Corrective Solutions in Transmission". Third Symposium on Expert Systems Applications, 1991. Tokyo-Kobe, Japan

[6] E Handschin. W Hoffman "Integration of an Expert System for Security Assessment into an Energy Management System" Electrical Power and Energy Systems, April/June 1992

[7] Stott, B., Alsac, O., "Fast decoupled load flow". IEEE Transactions on Power Apparatus and Systems. May 1.974, pp 859-867. 